\title{
Erratum: Zhou, S., et al. Warming Effort and Energy Budget Difference of Various Human Land Use Intensity: Case Study of Beijing, China. Land 2020, 9, 280
}

\author{
Shenghui Zhou ${ }^{1,2}$, Ke Wang ${ }^{1,2}$, Shiqi Yang ${ }^{1,2}$, Wenli Li ${ }^{1,2}$, Yuxuan Zhang ${ }^{2}$, Bin Zhang ${ }^{2}$, Yiming Fu ${ }^{2}$, \\ Xiaoyan Liu ${ }^{2}$, Yadi Run ${ }^{2}$, Oliva Gabriel Chubwa ${ }^{2}$, Guosong Zhao ${ }^{3} \mathbb{D}$, Jinwei Dong ${ }^{4}$ and and aping Cui $^{1,2, *(\mathbb{D})}$ \\ 1 Key Laboratory of Geospatial Technology for the Middle and Lower Yellow River Regions \\ (Henan University), Ministry of Education, Kaifeng 475004, China; zhou.shenghui@vip.henu.edu.cn (S.Z.); \\ wangke0904@vip.henu.edu.cn (K.W.); ysq0104@vip.henu.edu.cn (S.Y.); liwenli1118@vip.henu.edu.cn (W.L.) \\ 2 Key Laboratory of Integrative Prevention of Air Pollution and Ecological Security of Henan Province, \\ College of Environment and Planning, Henan University, Kaifeng 475004, China; \\ henu_hgzyx@vip.henu.edu.cn (Y.Z.); henu_zhangbin0825@vip.henu.edu.cn (B.Z.); \\ fym0521@vip.henu.edu.cn (Y.F.); lxy@henu.edu.cn (X.L.); run@henu.edu.cn (Y.R.); \\ olivachubwa@yahoo.com (O.G.C.) \\ 3 School of Geography and Information Engineering, China University of Geosciences, Wuhan 430074, China; \\ zhaogs.11b@igsnrr.ac.cn \\ 4 Institute of Geographic Sciences and Natural Resources Research, Chinese Academy of Sciences, \\ Beijing 100101, China; dongjw@igsnrr.ac.cn \\ * Correspondence: cuiyp@lreis.ac.cn; Tel.: +86-0371-23881850
}

check for updates

Citation: Zhou, S.; Wang, K.; Yang, S.; Li, W.; Zhang, Y.; Zhang, B.; Fu, Y.; Liu, X.; Run, Y.; Chubwa, O.G.; et al. Erratum: Zhou, S., et al. Warming Effort and Energy Budget Difference of Various Human Land Use Intensity: Case Study of Beijing, China. Land 2020, 9, 280. Land 2021, 10, 60. https://doi.org/10.3390/ land 10010060

Received: 31 December 2020 Accepted: 4 January 2021 Published: 12 January 2021

Publisher's Note: MDPI stays neutral with regard to jurisdictional clai$\mathrm{ms}$ in published maps and institutional affiliations.

Copyright: (C) 2021 by the authors. Licensee MDPI, Basel, Switzerland. This article is an open access article distributed under the terms and conditions of the Creative Commons Attribution (CC BY) license (https:// creativecommons.org/licenses/by/ $4.0 /)$.
The authors would like to change the authors' affiliation in the recent published paper [1] from:

Key Laboratory of Geospatial Technology for the Middle and Lower Yellow River Regions, Ministry of Education, Kaifeng 475004, China.

to the correct version, as follows:

Key Laboratory of Geospatial Technology for the Middle and Lower Yellow River Regions (Henan University), Ministry of Education, Kaifeng 475004, China.

The authors would like to apologize for any inconvenience caused to the readers by these changes. The changes do not affect any scientific result of the paper.

\section{Reference}

1. Zhou, S.; Wang, K.; Yang, S.; Li, W.; Zhang, Y.; Zhang, B.; Fu, Y.; Liu, X.; Run, Y.; Chubwa, O.G.; et al. Warming Effort and Energy Budget Difference of Various Human Land Use Intensity: Case Study of Beijing, China. Land 2020, 9, 280. [CrossRef] 